Milica Kisić

Snežana Božanić

Univerzitet u Novom Sadu

Filozofski fakultet

Odsek za istoriju

nekmoli@orion.rs

sbozanic5@gmail.com
Originalan naučni rad

primljeno: 1. jul 2012

prihvaćeno: 1. oktobar 2012

\title{
ODGOVOR DUBROVAČKOG VEĆA NA PISMO KRALJA ŽIGMUNDA OD 9. XI 1427: PREVOD I JEZIČKA ANALIZA*
}

Sažetak: Rad nakon osnovnog istorijskog uvoda iznosi originalni tekst, a potom i prevod pisma Dubrovačkog veća umoljenih Žigmundu Luksemburškom, kao odgovor na njegov pismeni poziv dubrovačkim trgovcima i zanatlijama od 9. novembra 1427 da u što većem broju, uz brojne ponuđene privilegije i slobode, dođu u Beograd koji je ugarski kralj iste godine preuzeo od Đurđa Brankovića. Sledi detaljna jezička analiza dotičnog tekstualnog uzorka, po svemu tipičnog za latinitet poznog srednjeg veka.

Ključne reči: sporazum u Tati, Beograd, Dubrovnik, Žigmund Luksemburški, srednjovekovni latinitet.

Maja meseca 1426. godine sklopljen je u Tati, banji na teritoriji Komoranske županije, sporazum između Žigmunda Luksemburškog i Stefana Lazarevića. Originalan dokument nije sačuvan, ali nam je po docnijim, po svemu sudeći prerađivanim prepisima poznato šta su odredbe dotičnog sporazuma podrazumevale: Stefan je tražio da, u slučaju svoje smrti bez zakonitih muških potomaka, Đurađ Branković bude priznat za naslednika srpskog prestola, te uvršten u red ugarske vlastele, što je povlačilo i njegovo pravo na nemale despotove posede u Ugarskoj. Žigmund je pak ostvarenje Stefanovih zahteva uslovio obnovom vazalnih odnosa Srbije prema Ugarskoj, ali i povratkom Beograda, Golupca, Mačve i oblasti zapadno od Drine pod ugarsku vlast. Odredba o predaji Beograda i danas ostaje u najmanju ruku zbunjujuća - nije, naime, jasna težnja Stefanova da i dalje (januar 1427) izgrađuje ovaj grad kao svoju prestonicu ukoliko je već bio prihvatio narečeni uslov ugarskog $\operatorname{kralja}^{1}$. Mnoge činjenice ukazuju na to da u leto i jesen

\footnotetext{
${ }^{*}$ Rad predstavlja fazni rezultat istraživanja za dva projekta: Vojvođanski prostor u kontekstu evropske istorije (br. 177002) finansiran od strane Ministarstva prosvete i nauke Vlade Republike Srbije i Srednjovekovna naselja na tlu Vojvodine. Istorijski procesi $i$ događaji, br. Rešenja 114-451-2216/2011, koji finansira Pokrajinski sekretarijat za nauku Vlade Autonomne pokrajine Vojvodine.

${ }^{1}$ Grupa autora, Istorija srpskog naroda, knjiga II, Beograd 1982, 215.
} 
1426. godine Srbija nije bila u ratnim odnosima sa Turskom. ${ }^{2}$

Naredna pak, 1427 godina, započela je višemesečnom turskom opsadom Novog Brda i okolnih naselja. Iste godine u julu od srčane kapi iznenada je preminuo Stefan Lazarević, a Đurađ Branković pohitao je u Beograd kako bi tamo sa Žigmundom sproveo odredbe sporazuma u Tati i time precizno definisao i utvrdio sopstveni položaj. Pri ovom susretu Đurađ je bio uvršten u red ugarskih barona, svečano priznat za Žigmundovog vazala, ali i vladara Srbije, a potom je ugarskom kralju, uz burno negodovanje srpskog stanovništva, «teška srca predao Beograd, dotadašnju prestonicu koju je despot Stefan toliko izgradio i unapredio ${ }^{3} »$. Suprotno sporazumu, Đurađ je zadržao Mačvansku banovinu, a Žigmund nije zaposeo ni Golubac, koji je buntovni vojvoda Jeremija, nakon neuspelog pokušaja pregovora sa Đurđem, predao Turcima.

U novembru 1427. ugarski kralj već je bio neprikosnoveni gospodar Beograda, budućeg važnog uporišta i bedema daljem nadiranju Turaka. Nastojao je svim silama da grad naseli katolički orijentisanim stanovništvom (braneći Srbima pristup Beogradu), te da ga održi ne samo kao vojni, već i kao značajan privredni centar. Upravo sa tim ciljem uputio je 9. novembra 1427. godine pismo Dubrovačkom veću, pozivajući tamošnje trgovce u Beograd i nudeći im brojne slobode i povlastice. Kako ćemo imati prilike da vidimo, dubrovačka vlada nije odmah bila kadra da odgovori Žigmundovim zahtevima: dobar broj trgovaca bio je izolovan u Novom Brdu i Prizrencu, pod teškom turskom opsadom, za koju smo već naglasili da je nastupila još početkom 1427. godine. Pismo Dubrovačkog veća - odgovor na narečeni Žigmundov poziv - preuzeto je iz: Mihailo Dinić, Građa za istoriju Beograda u srednjem veku, knjiga II, Beograd 1958, 20-21. Slede najpre originalni tekst pisma i prevod na srpski, a potom i podrobna leksička i morfosintaksička analiza ovog uzorka, tipičnog za pozni srednjovekovni latinitet, pri tome karakterističnog za područje Dubrovnika, pa time i - nadasve u pogledu sintakse - pod nemalim uticajem uveliko formiranog italijanskog jezika.

\footnotetext{
Domino nostro regi Romanorum et Hungarie [I]

Serenissime principum et excellentissime domine. Humili semper recommendacione [II] premissa [III]. Litteras maiestatis vestre [IV] reverenter ut solemus et debemus admisimus datas in castro Nandoralbensi die nono novembris anni presentis. Quas ut legimus et intelleximus sospitatem celsitudinis vestre et prosperos successus suos mirum in modum letati sumus [V] habundatissimas [VI] et fidellissimas gratias refferentes de novis que [VII] maiestas vestra dignata est notificare [VIII] nobis servitoribus suis et signanter [IX] ad eam partem [X] in qua celsitudo vestra declarat civitatem Nandoralbensem cum arce et castro in manibus tenere [XI] suis ut fines regni Hungarie illesos servet et regnum Rassie [XII] tuttare [XIII] possit. Quam civitatem [XIV] quia celsitudo vestra ampliare et augmentare [XV] desiderat et maxime in congregatione mercatorum et artificum ad spem maximam immunitatum et prerogativarum convocandorum $[\mathrm{XVI}]$ requirit fidelitatem nostram quod $[\mathrm{XVII}]$ mercatores cives nostros et fideles celsitudinis vestre hortari debeamus quod [XVIII] dirrigant mentem suam et mercantiarum suarum exercitia ad civitatem predictam [XIX]. Circa quam rem, serenissime princeps, non dubitamus serenitati vestre $[\mathrm{XX}]$ manifestum esse quanta sit numerositas simul et qualitas mercatorum huius vestre [XXI] civitatis Ragusii qui partim
}

\footnotetext{
${ }^{2}$ Ibid, 216.

${ }^{3}$ Ibid, 220.
} 
in opido[XXII] Nouimontis partim in vallo Priesrinac tot iam mensibus [XXIII] tam feliciter obsessi sunt tociens [XXIV] a Turchorum rabie debellati in maximo vite [XXV] periculo. Qui cum maximam mercantiarum summam inter illas partes sparsim locaverint atque serverint in nulla re alia nisi in solo Dei suffragio et in celsitudine vestra spem reponunt, a qua nisi celeriter sibi opportuno remedio succurratur vident propinqua nimis vite [XXVI] pericula et ammissionem bonorum quum si [XXVII] hucusque [XXVIII] se viriliter defenderunt [XXIX] recentiores ad pugnam, vivaciores in spe subsidii et opulenta munitione fulciti dubitamus [XXX] ne spe prostrati et victualibus suministratione [XXXI] attenuati tandem succumbant derelicti. Cuius rei expectatione atque tremore non modo ipsi qui obsidentur sed eorum quoque attinentes et sotii [XXXII] qui hic nobiscum habitant adeo perterrefacti sunt quod [XXXIII] potie mercantie [XXXIV] exercicium $[\mathrm{XXXV}]$ sit quodammodo derelictum expectantes quorsum [XXXVI] se vertat ista fortuna que [XXXVII] partim per [XXXVIII] attinentiam partim per collegantiam adeo universos amplectitur cives quod [XXXIX] si per peccata nostra ipsi concives nostri perderentur maximam partem civitatis et civium et mercantiarum plane intelligimus esse perituram. Itaque si opere, si potentia serenitatis vestre uti spreramus predicti fideles vestre serenitatis concives nostri de suis obsidionibus eruentur non dubitamus quod [XL] et in Nandoralbensi civitate et ubicumque sub umbra et protectione vestre celsitudinis fiducia maxima se reducent [XLI] ut familias et opportunitates suas substentare et facultates suas augmentare atque servare possint. Nam de reliquis concivibus nostris usque adeo venire non possent [XLII] cum eorum mercantiis ad civitatem illam quod nec vacui cursores litteras defferre queant ad obsessos cives nostros neque inde ad nos remeare propter itinera que rupta sunt tam per Bosnam quam per Sclauoniam et Albaniam. Quam ob rem ad clementissimam maiestatem vestram devotissima fiducia supplicamus quatenus [XLIII] eosdem cives nostros qui in tot et tantis suarum nostrarumque fortunarum periculis fluctuant dignetur suscipere tum opportunis cum desideratis subsidiis recommissos ut ipsi nobiscum nosque cum illis possumus [XLIV] ut optamus serenitati vestre gerere morem. Que vero mandat serenitas vestra apud corda nostra secretissima servari audacter fideliterque faciemus. De novis vero notificamus reverenter quod [XLV] inter sanctissimum dominum nostrum papam et serenissimum regem Aragonum nil [XLVI] ultra quam primo scripsimus secutum esse sentimus. De duce [XLVII] vero Mediolani cum colligatis diximus per alias nostras quod [XLVIII] reverendissimus cardinalis $S$. crucis exierat ad pacem tractandam de qua nichil [XLIX] conclusum fuit. Verum ex postea habuimus nova quod [L] de gentibus suis intercepti fuerunt [LI] mille equi per [LII] gentes colligatorum prout hec [LIII] et alia et dilucidius novisse deberet [LIV] vestra serenitas. Preterea cum oratores Venetorum ad maiestatem vestram venisse [LV] debeant supplicamus quod [LVI] in omnem cum eis praticam [LVII] hanc civitatem vestram membrum corone memorare dignetur vestra maiestas cuius pedibus nos humillime commendamus.

Datum Ragusii VIIII decembris 1427. V. M. F. ${ }^{4}$ Rector et Consilium Ragusii. In simili forma mutatis mutandis scriptum fuit domino Steffano de Rocgon comiti Temesiensi etc.

Lettere di Levante 10 (1427-30) fol. 35’. Gelcich - Thallóczy, Diplomatarium relationum reipublicae Ragusanae cum regno Hungariae 328-330.

Prevod:

Našem gospodaru, vladaru Svetog rimskog carstva i Ugarskog kraljevstva

\footnotetext{
${ }^{4}$ V. M. F. - vene (bene) merenti fecerunt; Adriano Cappelli, Dizionario di abbreviature latine ed italiane, Milano 1979, 512.
} 
Najsvetliji među vladarima i preuzvišeni gospodaru,

vazda Vam ponizno stojimo na usluzi. Baš kao i obično i kako nam valja činiti, uz puno poštovanje primili smo Vaše pismo iz Beograda od 9. novembra ove godine. Kada smo ga pročitali i tako saznali da je Vaša preuzvišenost dobroga zdravlja i da joj sve čega se pothvati ide od ruke, neobično smo se obradovali, a ovom prilikom se takođe iz sveg srca zahvaljujemo na novostima kojima je Vaše veličanstvo udostojilo nas, svoje podanike posebno na onom delu gde Vaša preuzvišenost javlja da je preuzela grad Beograd sa vojnim logorom i utvrđenjem, a sve kako bi sačuvala nepovredivost ugarskih granica, te bila kadra da odbrani kraljevstvo Raške. Budući da Vaša preuzvišenost želi da uveća i proširi narečeni grad, ona u pismu iziskuje i našu uslužnost u pogledu podsticanja ovdašnjih trgovaca i zanatlija, naših sugrađana a Vaših podanika, da, uz brojne privilegije i povlastice koje garantujete, preusmere svoje težnje i sprovođenje trgovine upravo na Beograd. Baš na tu temu, presvetli gospodaru, ne sumnjamo da je Vašoj svetlosti više no poznato da su brojni naši i izvrsni dubrovački trgovci već mesecima pod istrajnom opsadom Turaka, kako u Novom Brdu, tako i u Prizrencu, te da su, već izmoždeni od napada neprijateljske pošasti, u ozbiljnoj životnoj opasnosti. Pošto su oni najveći deo svoje robe bez ikakvog reda ostavili u okolini pomenutih naselja, sada sve nade polažu još samo samo u naklonost Božiju i Vašu visost: ukoliko im brzo i blagovremeno odatle ne stigne pomoć, bliži im se kraj i gubitak materijalnih dobara, jer - bez obzira na to što su se do sada odvažno branili, još uvek sveži, živahni i orni za borbu, sve uzdajući se u pomoć i čvrste gradske bedeme - bojimo se da će na kraju, izgladneli, lišeni svake nade i sasvim prepušteni sebi, podleći neprijatelju. U očekivanju raspleta i u opštoj strepnji do te mere smo pogođeni - i oni pod opsadom, i mi, njihovi rođaci, prijatelji i sugrađani - da je čitav Dubrovnik u privrednom smislu zamro u iščekivanju da se situacija konačno razreši: do te mere se ona, kako zbog osećaja bliskosti, tako i zbog elementarne solidarnosti, tiče svih nas da bismo propast pomenutih naših sugrađana i njihove robe uistinu doživeli kao sopstveni greh i potpuni krah. Stoga, ukoliko zahvaljujući moći i intervenciji Vaše svetlosti - a kako se mi i nadamo da će biti - naši sugrađani uspeju da se izvuku iz opsade, nema nikakve sumnje da će, uz izuzetnu uslužnost i odanost, doći kako u Beograd, tako i bilo kamo gde bi se našli pod zaštitom Vaše preuzvišenosti, a sve kako bi ne samo izdržavali svoje porodice, već i poboljšali i proširili sopstvene poslovne mogućnosti. Što se ostalih Dubrovčana tiče, oni nisu u prilici da sa robom dopru do Beograda zbog razrovanih i prekinutih puteva preko Bosne, Slavonije i Albanije. Situacija je takva da bukvalno nismo kadri da pošaljemo ni pismonoše lišene bilo kakve robe i tereta do naših sugrađana pod opsadom. Zato usrdno molimo Vaše milostivo veličanstvo da udostoji naše nesrećne i uistinu životno ugrožene sugrađane blagovremene i adekvatne pomoći kako bismo i mi oni mogli da udovoljimo željama Vaše svetlosti. Ono što pak Vaša svetlost nalaže da zadržimo u tajnosti, zadržaćemo odano i bez izuzetka. Što se novosti tiče, s poštovanjem Vas obaveštavamo da se između aragonskog kralja i presvetog gospodara našeg, pape, nije zbilo ništa novo - sve je još uvek onako kako smo Vas informisali u prethodnom pismu. O milanskom pak vojvodi i njegovim saveznicima već smo Vam javili: kardinal Sv. krsta pokušao je da sprovede mirovne pregovore sa njim, ali sporazum još uvek nije postignut. U međuvremenu smo doznali da su dotični saveznici oteli nekih 1000 konja od kardinalovih podanika, ali to, kao i druge novosti, Vaša svetlost zasigurno daleko bolje i podrobnije odavno zna. Budući da mletački legati već imaju obavezu da do Vas putuju svojim poslom, na kolenima molimo da razmotrite ovo pisano svedočanstvo koje će Vam tom prilikom predati, te im kažete i koju reč na temu ovog grada koji je pod zaštitom Vaše krune.

Izdato u Dubrovniku, 9. XII 1427. godine, sastavili dubrovački knez i Senat

U sličnoj formi, ali uz potrebne izmene pismo je upućeno i Stefanu Rozgonjiju 
I Hungarie $<$ Hungariae, pitanje ortografije: za srednjovekovni latinitet karakteristično je uprošćavanje diftonga, te njihovo zapisivanje onako kako se čitaju. Tek u doba Humanizma ponovo su zvanično uvedeni u ortografiju ${ }^{5}$.

II Recommendacione < recommendatione, ponovo deformacija ortografske prirode, a u skladu sa pravilima tradicionalnog čitanja grupe -ti ukoliko iza nje sledi vokal.

III Premissa < praemissa, princip kao u napomeni I.

IV Vestre < vestrae, pluralis maiestatis sa ortografskom deformacijom kao u prethodnoj napomeni.

V Letati sumus < laetati sumus, isto.

VI Habundatissimas < abundatissimas, tipičan primer hiperurbanizma, tj. hiperkorektnog zapisivanja, posledica ranog gubitka aspiracije na početku reči karakterističnog za vulgarni latinitet, ali i današnje romanske jezike ${ }^{6}$.

VII Que < quae, videti napomenu I.

VIII Notificare < nuntiare, kovanica karakteristična za hrišćanski latinitet kao prepoznatljiv sastavni element srednjovekovnog latinskog (uz, naravno, klasični i vulgarni latinitet). Zanimljivo je i to da je dotični glagol zadržao svoju strogo klasičnu rekciju: i dalje traži objekat u dativu («nobis servitoribus suis»).

IX Signanter < imprimis, praecipue.

X Ad eam partem < ei parti: srednjovekovni latinski preferira analitičke konstrukcije, ovde je namesto dativa na tipičan način upotrebljen predlog ad sa akuzativom.

XI Tenere < teneri: iako se akuzativ sa infinitivom, elegantna konstrukcija iz klasičnog latinskog sa vrednošću zavisno-izrične rečenice, gotovo izgubio u srednjovekovnom latinitetu, te bio smenjen frekventnim veznikom quod i zavisnom rečenicom u konjunktivu (po pravilima daleko labavijim no kod rimskih auctores), ovde se susrećemo upravo sa dotičnom konstrukcijom koju uvodi glagol declarare. Ipak, zbog smisla je bilo neophodno upotrebiti pasivni, a ne aktivni infinitiv prezenta kako je to u tekstu pisma učinjeno.

XII Rassie $<$ Rasciae

XIII Tuttare < tutor, I, -atus sum, morfološko prekrajanje tipično za vulgarni latinitet kao sastavni deo srednjovekovnog latinskog: izbegavanje «komplikovanosti» deponentnih glagola, te njihovo deformisanje u glagole što jednostavnijih konjugacija. Ovde se takođe susrećemo i sa pogrešnim zapisivanjem glagola geminatom -tt. Verovatno se radi o mešanju italijanskog glagola tutelare (sa istim značenjem) i njegovo pogrešno povezivanje sa pridevom tutto < totus koji je u italijanski prenesen sa geminatom iako je u izvornom latinskom pridevu nije bilo.

XIV Civitatem: civitas spada u grupu reči koje su u srednjovekovnom latinitetu promenile svoje značenje - ona sada ima smisao koji su nekada zapremale reči oppidum i urbs. Pojava je prvi put zabeležena u neformalnom jeziku Ciceronove prepiske sa bliskim prijateljima (Cic. Ad Fam. 9.9.3).

XV Augmentare < augere: ovde imamo posla sa prelaznim, vulgarnim oblikom koji je na koncu transformisan u italijanski glagol aumentare.

XVI Ad spem maximam immunitatum et prerogativarum convocandorum < ad spem maximam convocandi immunitatum et prerogativarum: kako je poznato, u klasičnom latinitetu na ovom mestu ne bi bila izvršena stilska intervencija zamene gerunda gerundivom kako bi se izbegla kakofonija gomilanjem nastavaka za genitiv množine. Srednjovekovni je latinski pak po pitanjima jezičkog purizma i stilistike vrlo ležeran.

XVII Quod < ut sa finalnim značenjem: veznik quod teži da u srednjovekovnom latinitetu postane neka vrsta univerzalnog veznika (nešto nalik današnjem italijanskog $\mathrm{che}^{7}$ ),

\footnotetext{
${ }^{5}$ Za opširnije informacije: Medieval Latin, ed. K. P. Harrington, Chicago \& London 1997, 1-51.

${ }^{6}$ Detaljnije: Giovanni Cremaschi, Guida allo studio del latino medievale, Padova 1959, 35-51.

${ }^{7}$ Detaljnije: Gordana Terić, Istorija italijanskog jezika, Beograd 1995, 266-273.
} 
smenjujući tako latinske veznike cum i ut sa njihovom širokom lepezom značenja. Takođe je i upotreba konjunktiva, pa i slaganja vremena vrlo slobodna. Ovde je ispravno upotrebljen konjunktiv prezenta koji bi u klasičnom latinitetu sledio finalno ut, budući da u nezavisnom delu rečenice imamo tzv. glavno vreme.

XVIII Quod < ut sa zahtevnim značenjem: ponovo i po identičnom principu imamo upotrebu veznika quod, ovoga puta u zavisno-zahtevnoj rečenici, opet ispravno praćeno konjunktivom prezenta.

XIX Predictam < praedictam, pogledati napomenu I.

$\mathrm{XX}$ i XXI Vestre < vestrae, isto.

XXII Opido < oppido

XXIII Tot iam mensibus < tot iam menses: klasični latinitet ovde bi upotrebio akuzativ vremenskog trajanja, razlikujući ga od ablativa vremena. Srednjovekovni pak latinitet pomenuti akuzativ smenjuje ablativom bez predloga, dok za ablativus temporis ima zamenu u vidu analitičke, predloške konstrukcije.

XXIV Tociens < totiens, pogledati napomenu II.

XXV i XXVI Vite < vitae, pogledati napomenu I.

XXVII Quum < cum; cum si < etiamsi, tametsi, quamquam: ovde imamo konfuziju tipičnu za srednjovekovni latinitet. Ne izostaje svest o postojanju složenih veznika koji, u koncesivnom kontekstu, u klasičnom latinskom bivaju praćeni indikativom, ali i veznika poput upravo cum koji u istom kontekstu idu uz konjunktiv. U tekstu pisma najpre je upotrebljeno cum u svom arhaičnom obliku (quum), a ono je potom praćeno veznikom si kako bi se u zavisno-dopunskoj klauzi ipak upotrebio od konjunktiva jednostavniji indikativ.

XXVIII Hucusque < huc usque.

XXIX Defenderunt: indikativ u zavisno-koncesivnoj rečenici, pogledati napomenu XXVII.

XXX Dubitamus ne... < timemus, metuimus, veremur, in timore sumus ne: iz konteksta postaje savršeno jasno da bi klasični latinitet ovde preferirao verbum timendi sa veznikom ne i konjunktivom.

XXXI Suministratione $<$ sumministratione $<*$ subministratione

XXXII Sotii $<$ socii: opet tipičan primer hiperkorektne ortografije.

XXXIII Quod < ut sa posledičnim značenjem: ponovo imamo upotrebu "univerzalnog” veznika srednjovekovnog latiniteta, ovoga puta u konsekutivnom kontekstu. U nezavisnom delu rečenice postoji prilog-marker adeo koji najavljuje zavisno-posledičnu rečenicu. Specifičnost tzv. apsolutne upotrebe konjunktiva u zavisno-posledičnim rečenicama ovde je očuvana po pravilima klasičnog latiniteta.

XXXIV Mercantie < mercantiae: videti napomenu I.

XXXV Exercicium < exercitium: videti napomenu II.

XXXVI Quorsum < dum, donec sa konjunktivom prezenta: klasični latinitet je uz temporalni veznik dum ili donec upotrebljavao konjunktiv prezenta ili imperfekta kako bi time naglasio subjektivnu nameru ili očekivanje vršioca radnje glavne rečenice. U našem tekstu konjunktiv se očuvao, ali uz vrlo nesrećno izabran veznik.

XXXVII Que < quae: videti napomenu I.

XXXVIII Per $<$ propter, ob

XXXIX Quod < ut sa konsekutivnim značenjem: pogledati napomenu XXXIII.

XL Quod < AccI: iza izraza non dubitamus, klasični latinitet upotrebio bi konstrukciju akuzativa sa infinitivom u svojstvu zavisno-izrične rečenice. Ovde pak srećemo veznik quod analogan italijanskom che, o čemu je već bilo reči.

XLI Reducent: ovde je upotrebljen indikativ futura namesto, kako smo maločas naglasili, akuzativa sa infinitivom, odnosno perifrastične konjugacije aktivne u konjunktivu prezenta kako bi to bilo prirodno u klasičnom latinskom. Insistiranje na upotrebi indikativa ukazuje pak na osetljivost srednjovekovnog latinskog na, u ovom konkretnom slučaju, sintaksu italijanskog jezika: zavisno-izrične rečenice u italijanskom zapravo 
povlače za sobom konjunktiv. Izuzetak su ipak rečenice koje slede nakon posebno naglašenih izraza sigurnosti subjekta nezavisne klauze, što je upravo naš slučaj ${ }^{8}$.

XLII Possent < possunt: posve neopravdana upotreba konjunktiva imperfekta u nezavisnoj klauzi na koju se potom oslanja zavisno-uzročna rečenica u kojoj je upotreba konjunktiva sasvim umesna.

XLIII Quatenus < ut sa zahtevnim značenjem: veznik quatenus namesto očekivanog ut sa finalnim ili zahtevnim smislom frekventna je i stara karakteristika srednjovekovnog latiniteta. Prvi put zabeležena je još u delima Avgustina i Ambrozija.

XLIV Possumus < possimus: ovde, nakon veznika ut sa namernim značenjem, adekvatno bi bilo da usledi konjunktiv prezenta, no, kako je već bilo reči, srednjovekovni latinitet vrlo je ležeran u pogledu dotičnih regula.

XLV Quod: ovde sa izričnim značenjem. Pojava je podrobnije rasvetljena u napomenama XL i XVI. Posebna zanimljivost ovog slučaja je da nakon veznika quod sledi glagol percepcije koji potom, po pravilima klasičnog latinskog, za sobom povlači konstrukciju akuzativa sa infinitivom. Imamo, dakle, posla sa pleonastičnom strukturom dvostruke zavisno-izrične rečenice.

XLVI Nil < nihil: ortografija sledi izgovor. Pojava je uočena vrlo rano i karakteristična je za vulgarni latinitet.

XLVII Duce: imenica dux menja u srednjem veku svoj prvobitni smisao i sada označava titulu vojvode.

XLVIII Quod: pogledati napomene XL i XLI.

XLIX Nichil < nihil

L Quod: pogledati napomene XL i XLI.

LI Intercepti fuerunt < intercepti erant: upotrebljeno vreme ne postoji. Najverovatnije se težilo naglašavanju činjenice da se događaj o kojem se govori zbio znatno ranije (što je, uostalom, i naglašeno podvlačenjem da se radi o starim, već prevaziđenim novostima koje Žigmund zasigurno odavno doznao), a to se postiže upotrebom pluskvamperfekta, ovde nepravilno sagrađenog u pasivu.

LII Per gentes colligatorum < a gentibus colligatorum: mešanje funkcija ablativa i akuzativa frekventna je pojava u srednjovekovnom latinitetu.

LIII Hec < haec: videti napomenu I.

LIV Prout novisse deberet < prout novisse debet: u klasičnom latinskom poredbeno ut / prout praćeno je indikativom. Ovde se susrećemo sa uobičajenom srednjovekovnom konfuzijom na temu upotrebe konjunktiva.

LV Cum oratores Venetorum venisse debeant < cum oratores Venetorum venire debeant: ovde se susrećemo sa zavisno-uzročnom rečenicom u konjunktivu upotrebljenom po pravilima klasičnog latinskog, no i sa posve neumesnim aktivnim infinitivom perfekta glagola venire, oslonjenim na debere. Reč je najverovatnije o pogrešci čiji uzrok leži u povođenju za prethodnom rečenicom u kojoj smo imali «novisse deberet» - sasvim adekvatno upotrebljen infinitiv (takođe naslonjen da debere), budući da se radi o defektnom glagolu novi, novisse koji ima isključivo oblike perfekatske osnove.

LVI Quod < ut sa zahtevnim značenjem: pogledati napomenu XVII.

LVII Pratica $<*$ practicus, $3,<* \pi \rho \alpha \kappa \tau \iota \kappa o ́ \varsigma, ~ 3$ : reč se kao imenica pojavljuje isključivo u srednjovekovnom latinitetu. Njeno grčko poreklo više je nego očigledno. Znači pisano svedočanstvo ${ }^{9}$.

\footnotetext{
${ }^{8}$ Pietro Trifone-Massimo Palermo, Grammatica italiana di base, Bologna 2007, 205-207.

${ }^{9}$ Du Cange, Glossarium mediae et infimae latinitatis, tomus VI, Niort 1883: pratica - quae manibus exercetur; A. Bartal, Glossarium mediae et infimae latinitatis regni Hungariae, Budapest 1901: pratica - litterae testimoniales.
} 
Izvori i literatura:

Izvori:

Grupa autora, Istorija srpskog naroda, knjiga II, Beograd 1982.

Dinić, M., Građa za istoriju Beograda u srednjem veku, knjiga II, Beograd 1958.

Cappelli, A., Dizionario di abbreviature latine ed italiane, Milano 1979.

Medieval Latin, ed. Harrington, K. P., Chicago \& London 1997.

Literatura:

Bartal, A., Glossarium mediae et infimae latinitatis regni Hungariae, Budapest 1901.

Cange, Du, Glossarium mediae et infimae latinitatis, tomus VI, Niort 1883.

Cremaschi, Giovanni, Guida allo studio del latino medievale, Padova 1959.

Terić, Gordana, Istorija italijanskog jezika, Beograd 1995.

Trifone, Pietro, Palermo, Massimo, Grammatica italiana di base, Bologna 2007. 


\title{
A RESPONSE OF THE DUBROVNIK SENATE CHAMBER TO THE LETTER OF KING SIGISMUND FROM 9 NOVEMBER 1427: TRANSLATION AND LINGUISTIC ANALYSIS
}

\begin{abstract}
Summary
If the later transcripts of the original documents could be trusted, the agreement in Tati, from May 1426, which was reached between Stefan Lazarević and Sigismund of Luxembourg, obliged the Serbian despot to promise, among other things, to confer Belgrade to the king of Hungary after his death, in order to recognize Đurađ Branković for his legal heir and the future landlord of rather big despot's territories in Hungary. After taking over the city, which was the future important military stronghold and rampart for the further progress of Turks, Sigismund tried to inhabit it with the Catholic population, transferring it to an important trade center. With that purpose, he sent the letter to the Dubrovnik Senate Chamber on 9 November 1427, urging the local merchants and artisans to come in large numbers with their goods to Belgrade. The paper presents a genuine text of the letter-response of the Senate Chamber to the Hungarian king, and its translation into Serbian. It was found out that Dubrovnik inhabitants were not able to immediately respond to Sigismund 's requirements: most merchants and artisans were isolated, being in danger within the walls of Novo Brdo and Prizrenac, where they defended the mentioned villages of persistent Turkish invasion together with Serbs since the beginning of 1427. The paper contains a detailed lexical, and morphological and syntax analysis of the text as a typical sample of Latin influence in the late middle age, with all the very specific characteristics of the Dubrovnik area.
\end{abstract}

Keywords: agreement in Tati, Belgrade, Dubrovnik, Sigismund of Luxembourg, the medieval Latin influence. 